\title{
POLÍTICA URBANA E O DIREITO FUNDAMENTAL À MORADIA
}

Urban policy and the fundamental right to housing

Rodrigo Diego Jansen ${ }^{1}$

\begin{tabular}{|c|c|}
\hline RESUMO & ABSTRACT \\
\hline $\begin{array}{l}\text { Este artigo apresenta uma reflexão sobre o direito } \\
\text { fundamental à moradia no Brasil garantido } \\
\text { constitucionalmente e que reflete os anseios da } \\
\text { Sociedade pela efetivação de tão relevante direito, } \\
\text { além de demonstrar a ideologia adotada pelo modelo } \\
\text { constitucional no período da redemocratização do país. } \\
\text { O direito à moradia responde a uma necessidade } \\
\text { primária do homem, condição indispensável para uma } \\
\text { vida digna, eis que a casa é o asilo inviolável do } \\
\text { cidadão, a base de sua individualidade. Além disto, o } \\
\text { direito à moradia é considerado um direito } \\
\text { fundamental, não só porque está assegurado } \\
\text { constitucionalmente, mas também porque responde a } \\
\text { uma necessidade fundamental do Homem. }\end{array}$ & $\begin{array}{l}\text { This article presents a reflection on the fundamental } \\
\text { right constitutionally guaranteed housing in Brazil and } \\
\text { reflects the wishes of the Society for the realization of } \\
\text { such a relevant law, as well as demonstrate the } \\
\text { ideology adopted by the constitutional model during } \\
\text { the democratization of the country. The right to } \\
\text { housing responds to a primary need of man, a } \\
\text { prerequisite for a dignified life, behold, the home is the } \\
\text { inviolable asylum of the citizen, the basis for their } \\
\text { individuality. Moreover, the right to housing is } \\
\text { considered a fundamental right, not only because it is } \\
\text { constitutionally guaranteed, but also because it } \\
\text { answers a fundamental human right. }\end{array}$ \\
\hline $\begin{array}{l}\text { Palavras-chave: Direito fundamental. Direito } \\
\text { fundamental social. Direitos sociais. Políticas públicas. } \\
\text { Moradia. }\end{array}$ & $\begin{array}{l}\text { Key words: Fundamental right. Fundamental social } \\
\text { right. Social rights. Public policies. Habitation. }\end{array}$ \\
\hline
\end{tabular}

\section{Introdução}

A precariedade da habitação é, lamentavelmente, um dos problemas mais graves da sociedade brasileira, representando um dos custos mais caros nas sociedades contemporâneas submetidas ao sistema capitalista. Em um país com população predominantemente pobre e com capacidade comprometida para investimentos públicos, a habitação popular usualmente apresenta soluções temerárias, assistencialistas, dissonantes de condições dignas e sem qualquer segurança jurídica da posse. Nessas condições, por mais que esteja previsto no texto constitucional, não há como construir uma sociedade livre, justa e solidária, erradicar a pobreza e a marginalização, reduzir as desigualdades sociais e regionais e promover o bem de todos.

\footnotetext{
1 Fundação Universidade Regional de Blumenau (FURB) e Instituto Blumenauense de Ensino Superior (IBES/SOCIESC) r.jansen@terra.com.br
} 
162

Embora o sistema jurídico estatal parta do pressuposto de que todos os homens são iguais, há grupos sociais vivenciando que a igualdade propalada pelo Estado é uma mera ficção. Essa realidade impõe ao Estado brasileiro, que desde a sua origem se caracterizou por ser absenteísta, uma atuação intensa e direta em prol da moradia, por tratar-se de um requisito indispensável à vida e ao desenvolvimento nacional sustentável.

$\mathrm{O}$ direito à moradia foi consagrado no ordenamento jurídico brasileiro pela Emenda Constitucional $n^{\circ} 26$ de 2000. Referida Emenda expressa a competência Parlamentar para alterar a Constituição Federal e reflete os anseios da Sociedade pela efetivação de tão relevante direito, além de demonstrar a ideologia adotada pelo modelo constitucional no período da redemocratização do país.

$\mathrm{O}$ direito à moradia responde a uma necessidade primária do homem, condição indispensável para uma vida digna, eis que a casa é o asilo inviolável do cidadão, a base de sua individualidade, é, acima de tudo, como apregoou Edwark Coke, no século XVI "a casa de um homem é o seu castelo" (Nolasco: 2008, p. 87).

Por tal razão, este artigo tem como objetivo analisar a questão do direito à moradia, bem como as políticas públicas que devem ser adotadas pelo Estado para a concretização desse direito.

\section{Fundamentos e conceitos do direito à moradia}

O direito à moradia consiste na posse exclusiva e, com duração razoável, de um espaço em que se tenha proteção contra a intempérie e, com resguardo da intimidade, as condições para a prática dos atos elementares da vida: alimentação, repouso, higiene, reprodução e comunhão. Trata-se de direito erga omnes.

Seguindo o entendimento de Nolasco (2008, p. 87):

A moradia é o lugar íntimo de sobrevivência do ser humano, é o local privilegiado que o homem normalmente escolhe para alimentar-se, descansar e perpetuar a espécie. Constitui o abrigo e a proteção para si e os seus; daí nasce o direito à sua inviolabilidade e à 
constitucionalidade de sua proteção. Há vínculo de dependência entre esses dois direitos. $\mathrm{O}$ direito à moradia tende ao direito de morar e só se satisfaz com a aquisição deste em sua plenitude. Para isto, é preciso que concorram todos os elementos da moradia. Quem conseguiu terreno, mas não a casa, satisfez apenas em parte seu direito à moradia. O mesmo acontece com quem possui a casa, mas não por tempo suficiente, exigido pelas demais relações da vida (trabalho, convívio, cultura, educação dos filhos). Assim, ao direito de morar são extensivos os mesmos princípios que ordenam o direito à moradia.

$\mathrm{O}$ direito à moradia é considerado um direito fundamental em virtude de seu caráter a-histórico, pois o caráter de fundamentalidade não tem nenhuma implicação histórica. Direito à moradia é direito fundamental, não só porque está assegurado constitucionalmente, mas também porque responde a uma necessidade fundamental do Homem.

A moradia adequada é um direito que vem sendo construído no seio da comunidade política e se adensando pela legislação e pela jurisprudência brasileira.

O direito à moradia também é considerado imprescritível já que a prescrição é um instituto jurídico que somente atinge o exercício dos direitos de caráter patrimonial, mas não a exigibilidade dos direitos personalíssimos extrapatrimoniais, ainda que individuais.

Considera-se também ser o direito à moradia irrenunciável, pois, como direito humano fundamental deve ser interpretado como possibilidade, da pessoa, de viver de modo adequado à condição humana, ou seja, com direito à alimentação, ao vestuário, à assistência médico-odontológica, à educação, à cultura, ao lazer, à moradia e às demais condições vitais. Pode-se concluir que o Estado tem o dever de garantir o direito à moradia, em nível adequado à condição humana, respeitando os princípios fundamentais da cidadania, a dignidade da pessoa humana e os valores sociais do trabalho e da livre iniciativa, intitulados constitucionalmente.

Outra característica do direito à moradia é a ilicitude de sua violação. 
164

Há a violação do direito à moradia sempre que for implantado um sistema infraconstitucional ou qualquer ato advindo de autoridade pública que importe em lesão a esse direito, em redução, desproteção ou atos que inviabilizem o seu exercício, porque o direito à moradia goza de proteção (por intermédio dos três poderes) de respeitar, proteger, ampliar e facilitar esse direito fundamental. Dessa forma, toda e qualquer legislação infraconstitucional que suprima, dificulte ou impossibilite o exercício do direito à moradia por um indivíduo tem-se a sua violação - ainda que por norma validamente constituída e promulgada - é tida como violadora do direito à moradia. (Souza: 2008, p. 117).

Vale citar, ainda, que o direito à moradia é universal, pois a sua abrangência engloba todos os indivíduos, independentemente de qualquer outro requisito, tal como sexo, raça, credo, convicção político-filosófica ou sua condição econômica. (Souza: 2008, p. 118).

A atuação do Poder Público deve garantir a efetividade desse direito constitucionalmente previsto, com mecanismos coercitivos, já que a Constituição da República Federativa do Brasil de 1988 não se satisfaz abstratamente com o simples reconhecimento de um direito. Portanto, apesar de ter o direito à moradia aplicação imediata, surge o dever estatal de proteger e facilitar o seu pleno exercício, e as normas infraconstitucionais também devem atuar em conjunto com a norma constitucional, protegendo e facilitando o exercício desse direito.

Em síntese, pode-se afirmar que a inclusão do direito à moradia como um direito social fundamental permite maior eficácia e efetividade da legislação constitucional, no sentido de preservá-lo, a fim de proteger o indivíduo, sem que, sob o pretexto de proteger a coletividade, este direito seja sacrificado. Significa dizer que não se justifica o sacrifício do direito à moradia de uma pessoa ou de algumas delas, sob o pretexto do benefício social. Se o direito à moradia fosse incluído apenas como direito individual, teria fragilidade diante do interesse da função social que o limita. Desta forma, a função social do direito fundamental à moradia destina-se ao grupo familiar. 


\section{A realidade social brasileira e o direito à moradia}

As ocupações irregulares e ilegais estão presentes na maioria dos Municípios brasileiros, demonstrando uma triste realidade social que é a falta de moradia. No entanto, o problema não diz respeito somente à falta de imóveis para se morar, mas também a ausência de segurança da posse, que por sua vez, favorece a péssima qualidade com que são construídos os imóveis existentes, em especial nas áreas ilegais. (Holz e Monteiro: 2008).

Os dados estatísticos do Banco Mundial informam que de 1 milhão de moradias produzidas no Brasil, cerca de 700 mil são ilegais, o que comprova que a maior parte da produção habitacional no país é informal. Tais dados demonstram a tolerância do setor público com essa ilegalidade, porquanto na legislação brasileira o registro do imóvel é constitutivo de propriedade, valendo a máxima "quem não registra não é dono". Diante disso, uma das maiores implicações desse processo se refere à insegurança jurídica perante a moradia, que deixa a população residente dessas áreas numa situação de vulnerabilidade.

O mercado imobiliário capitalista, os baixos salários e a desigualdade social presente desde o início da formação da sociedade brasileira impossibilitam o acesso à moradia para grande parte da população, que principalmente nas últimas décadas, vêm sendo produto e produtor dos processos de periferização, segregação, degradação ambiental, má qualidade de vida e violência nas cidades.

Para Holz e Monteiro (2008), a realidade brasileira é que a excessiva valorização agregada às áreas centrais da cidade (que recebiam melhor tratamento urbanístico por parte dos governantes, sendo equiparadas com saneamento básico, iluminação pública, pavimentação das ruas etc.), fez com que os moradores mais necessitados não tivessem condições de adquirir imóveis nestas áreas. Desta maneira, a população que tinha condições de pagar, morava na "cidade formal", enquanto a população desprovida de recursos financeiros habitava a "cidade informal", concluindo-se que a "ilegalidade é subproduto da regulação tradicional e das violações contra os direitos à terra e à moradia".

Pochamann e Amorim (2003, p. 22) destacam que, o Brasil é lugar comum afirmar que a desigualdade impera, sendo mais evidenciada ao se observar os indicadores de inclusão/exclusão sociais. Os autores estudam a exclusão social e destacam que na região 
166

acima do trópico de capricórnio, nas regiões norte e nordeste, encontram-se a maioria dos municípios em situação intensa de exclusão social. Para os autores tal fato é resultado de uma velha exclusão social oriunda de um sistema de trabalho escravista e pela ausência de reformas clássicas do capitalismo contemporâneo, tornando o capitalismo brasileiro uma máquina de produção e reprodução de desigualdades.

Os referidos autores (Pochamann e Amorim: 2003, p. 24) afirmam, ainda, que, nas outras regiões a situação aparentemente não é tão intensa, uma vez que existe um maior número de ilhas de inclusão, sendo que as regiões do centro-sul apenas apresentam formas mais sofisticadas de exclusão, chamando-a de "nova exclusão social", herança do modelo econômico neoliberal, que gerou desde os anos 90 uma grande quantidade de desempregados escolarizados e famílias monoparentais que vivem na pobreza por ausência de renda.

Portanto, a regularização fundiária é um desafio da política habitacional social, sobretudo porque a Constituição Federal instituiu um capítulo destinado à Política Urbana, no qual a regularização fundiária é destacada por meio da função social da propriedade como política de habitação social.

A articulação entre Estado e Sociedade possibilitará o movimento de mudança ou transformação da realidade social.

\section{O Estatuto da Cidade e a questão da moradia}

A origem do problema de acesso à moradia urbana está intimamente ligada à falta de planejamento Estatal. O planejamento e as políticas públicas, no entanto, não são faculdades do administrador, mas sim, um dever constitucional, pois é sua competência implantá-las e também definir os objetivos determinados em função da realidade local.

Embora o planejamento seja uma obrigação de todos os entes da federação, não podem os Municípios ficar esperando ações da União e dos Estados, pois compete a eles a identificação dos seus problemas, demandas e potenciais, de forma que possam fixar metas e identificar os instrumentos que serão utilizados para que tais metas sejam alcançadas, vez que as pessoas não residem na União, nem nos Estados, mas, efetivamente, nos Municípios. 
A missão da Administração Pública Municipal não diverge daquela prevista no artigo 182 da Constituição da República Federativa do Brasil de 1988, porquanto possui a missão de garantir o bem-estar de seus habitantes e ordenar o pleno desenvolvimento das funções sociais da cidade. Segundo Patrícia Marques Gazola:

Para atender a essa missão, faz-se necessária a elaboração de diagnósticos setoriais e integrados da área de intervenção e seu entorno, abrangendo os aspectos urbano, ambiental, fundiário e social. Para a obtenção do diagnóstico temos vários métodos, que deverão ser utilizados complementarmente, vez que isoladamente não são capazes de demonstrar com exatidão a realidade da área. Com o método do desenvolvimento histórico levanta-se o histórico do desenvolvimento e ocupação da cidade; o método do mapeamento cadastral identifica em mapa as características urbanísticas “[...] elabora uma série de mapas (de uso do solo, de área construída, de áreas verdes existentes, etc.) [...]; no método da quantificação universal, tudo é quantificado e transformado em tabelas, quadros e diagramas; e o método da leitura direta implica na pesquisa de campo, mediante questionários e entrevistas. (Gazola, 2008, p. 77).

O sucesso das políticas públicas depende fundamentalmente de sua adequação às necessidades dos beneficiários. Logo, mister se faz à observância da fundamental diretriz que impõe a participação popular. Conforme já salientado, os principais instrumentos legais para a efetivação do direito à moradia se encontram previstos no Estatuto da Cidade, dentre os quais se destacam os Conselhos Municipais, Estaduais e Nacional de desenvolvimento urbano, as audiências públicas e a gestão orçamentária participativa.

A implementação de diretrizes políticas comprometidas possibilita à população o acesso à Administração Pública, a fim de que não somente participe da tomada das decisões, mas que também lhe seja possibilitado o controle da execução das mesmas. A viabilização de tais práticas dá aos cidadãos um espaço para discussão, apresentação de ideias e 
168

reivindicações dos serviços públicos que lhes são necessários, deixando de ser meros espectadores das decisões dos órgãos públicos.

No tocante às políticas públicas e ao direito à moradia, pode-se concluir que todas as medidas que foram e estão sendo tomadas pelo Estado brasileiro buscam enfrentar um dos seus maiores problemas sociais - o déficit habitacional - que hoje está estimado em 6,6 milhões de moradias. Luiz Cláudio Romanelli (2008, p. 97) argumenta que, além desse déficit nominal, estima-se a existência de 12 milhões de moradias impróprias ou precárias. Este quadro é agravado pela inexistência de recursos públicos que assegurem o acesso à moradia da população de baixa renda, pois $92 \%$ do déficit habitacional é composto de famílias com renda de até 5 salários mínimos. Estima-se, ainda, que 28\% do total dos domicílios estejam inadequados, ou seja, sem ao menos usufruir um dos serviços essenciais. Deste montante, $39,1 \%$ localizam-se no Nordeste. O serviço mais deficitário nos domicílios brasileiros é o esgoto sanitário (79,3\%), seguido da falta da rede geral de abastecimento de água (25,3\%). Este quadro indica a necessidade imediata da implementação de políticas habitacionais, alicerçadas nos instrumentos do Estatuto da Cidade, para a construção de novas unidades, para repor o estoque degradado e precário de habitações, melhoria das condições de infraestrutura e a implantação de programas de regularização fundiária.

Diante desse quadro, fica evidente que a implantação de políticas habitacionais torna-se ainda mais urgente, ante a constatação de que a maioria da população pobre ${ }^{2}$ não dispõe de renda suficiente para atender às condições de financiamento para a aquisição da casa própria, o que indica a necessidade de adoção de uma política de subsídios à habitação popular.

O Estatuto da Cidade também atribui grande importância ao Plano Diretor do Município, um dos instrumentos mais importantes na definição de políticas públicas de habitação, conforme passa-se a analisar.

\footnotetext{
22 População pobre pode ser investigada tanto em seu aspecto unidimensional (insuficiência de renda) quanto em seu aspecto multidimensional (privação das capacidades, ou seja, a capacidade dos indivíduos de exercer suas liberdades). A pobreza vista como ocorrência de baixa renda, é uma abordagem unidimensional, e é encarada como níveis de renda incapazes de atender as necessidades básicas. Conf. TEIXEIRA, Gilmara Emília. Pobreza e desigualdade de renda: Disponível em: http://www.cedeplar.ufmg.br/seminarios/seminario-diamantina/2006/DO6A100.pdf. Acesso em: 28 de dez. 2011.
} 


\section{Plano diretor}

Para garantir a efetividade do direito à moradia, o Estatuto da Cidade elegeu o Município como o ente federativo competente para definição da política urbana, cumprimento da função social da cidade e para a implementação da gestão democrática, a qual tem como instrumento básico de sua política urbana o Plano Diretor, consoante artigo $182, \S 1^{\circ}$ da Constituição da República Federativa do Brasil de 1988.

O processo de elaboração do Plano Diretor é uma das preocupações democráticas do Estatuto da Cidade.

A Constituição de um sistema de gestão democrática da cidade no Município é condição essencial para os objetivos da política urbana serem atingidos, através da aplicação do plano diretor, uma vez que o processo de formulação e execução das políticas públicas, o planejamento municipal e o modelo de gestão da cidade são matérias para a execução do plano diretor. (Saule, 1997, p. 69).

Hely Lopes Meireles (2003, p. 513) conceitua o plano diretor como um complexo de normas legais e diretrizes técnicas para o desenvolvimento global e constante do Município, sob os aspectos físico, social, econômico, e administrativo, desejado pela comunidade local. Deve ser expressão das aspirações dos Municípios quanto ao progresso do território municipal no seu conjunto cidade-campo.

Nolasco (2008) argumenta que o papel primordial do plano diretor é a efetivação da função social da propriedade urbana, que ocorre quando esta atende às exigências fundamentais de ordenação da cidade expressa no plano diretor, assegurando o atendimento das necessidades dos cidadãos quanto à qualidade de vida, à justiça social e ao desenvolvimento das atividades econômicas.

O Município, em razão de ser o principal ente federativo responsável pela execução da política urbana, tem a responsabilidade de desenvolver uma política habitacional de âmbito local. 
170

O Município tem o dever de desenvolver políticas públicas de âmbito local que garantam aos cidadãos o direito à moradia digna, estabelecendo as diretrizes e os instrumentos sobre o uso e a ocupação do solo urbano, bem como formas de cooperação entre o setor público e o privado a fim de resguardar os direitos fundamentais dos cidadãos.

\section{Os instrumentos previstos no Estatuto da Cidade para a concretização do} direito à moradia

Na busca de soluções à questão habitacional impende considerar os instrumentos previstos no Estatuto da Cidade para essa finalidade específica. Tais instrumentos estão previstos no artigo $2^{\circ}$ do referido instrumento legal.

A partir das diretrizes contidas no artigo $2^{\circ}$, é possível identificar, de modo mais ou menos direto, algumas das condições alternativas que alcançam o direito à produção habitacional. Em verdade, todo o rol ali disposto toca, em graus variáveis, a questão habitacional.

Importante, ainda, fazer menção às Leis Federais ns. 6.766 de 19 de dezembro de 1979 e 10.098 de 19 de dezembro de 2000. A primeira traz normas gerais sobre o parcelamento do solo para fins urbanos, bem como normas específicas que buscam facilitar o loteamento para população de baixa renda e a regularização de tais empreendimentos. A segunda lei contempla regras a serem observadas na "construção da cidade", de modo a assegurar a acessibilidade às pessoas portadoras de deficiência física ou com mobilidade reduzida. Na realidade, toda e qualquer moradia precisa ser produzida dentro desse marco legal nacional.

Do exposto resta claro a importância das políticas públicas e da gestão urbana para o enfrentamento dos déficits habitacionais; déficits estes não só quantitativos quanto qualitativos.

O direito fundamental à habitação só será garantido pela efetividade das políticas públicas, em especial a política habitacional. 


\section{Síntese crítica do comprometimento do Estado face à realidade social}

A questão habitacional é um problema do indivíduo e da sociedade, que está relacionada ao exercício de outro direito: o direito à vida. A propósito, Souza $(2008$, p. 118) destaca:

Há muito que o ser humano deixou de ser nômade e de ter uma vida precária. Assim, ao observar que o seu alojamento num lugar fixo the traria melhores resultados de continuidade ao seu desenvolvimento sociocultural e econômico, optou pela moradia fixa.

O instituto da moradia sofreu grandes mutações, visto que, com o crescimento populacional, o acesso a este bem passou gradativamente a ser restringido a determinados grupos, em decorrência do estado de miserabilidade de outros. Ocorre que o direito à moradia está referido à sobrevivência humana, portanto, inteiramente relacionado com a própria dignidade da pessoa humana.

No Brasil, o problema da habitação começou a ser sentido pelo Estado no final do Império, em decorrência das crescentes manifestações abolicionistas, até a sua devida concretização.

Após a segunda metade do século XVIII, com a Revolução Francesa, surgiu a Declaração dos Direitos do Homem e do Cidadão de 1789, e a moradia que, até então, se restringia à esfera privada, torna-se uma das preocupações do Estado. Os Estados foram incumbidos, com a Declaração, de se submeterem à máxima dos direitos humanos, que visavam concretizar a liberdade, a igualdade e a fraternidade. No século passado até a década de 30 a interferência estatal no âmbito habitacional foi mínima, limitando-se tão somente à medida de cunho sanitarista, objetivando diminuir as más condições de higiene das moradias dos trabalhadores. No entanto, foi a partir do intervencionismo estatal do Governo de Getúlio Vargas, mais precisamente em seu segundo governo (Estado Novo), que a política habitacional sofreu transformações significativas. 
172

Com o avanço da industrialização e o deslocamento do centro dinâmico da economia para a área urbana, houve um crescente descompasso entre a declinante disponibilidade de espaço habitável e sua elevada demanda. Diante dessa situação, o Estado, por meio do Decreto-lei n. 4.508, de 23 de julho de 1942, viu-se obrigado a intervir na oferta da moradia por meio da criação dos Institutos de Aposentadorias e Pensões (IAPs) dentro do Sistema de Previdência Social instituído no país naquele período.

Também no governo de Getúlio Vargas, tentando atender à demanda por habitação, foi criada, através do Decreto-lei n. 9.777, de 06 de setembro de 1946, a Fundação da Casa Popular (FCP), a qual visava atender à população que participava do mercado formal de trabalho, mas não era vinculada aos IAPs.

Com a Lei n. 1.300, de 28 de dezembro de 1950, que alterou a Lei do Inquilinato e vigorou da data da sua publicação até 31 de dezembro de 1951, verificou-se um declínio de programas habitacionais. No ano de 1961, foi criado o Plano de Assistência Habitacional, cuja principal inovação consistia na instituição da proporcionalidade entre a prestação do financiamento da casa própria e o salário mínimo.

Durante a ditadura militar foi criado o Banco Nacional da Habitação (BNH), por meio da Lei n. 4.380, de 21 de agosto de 1964, o qual tinha como função realizar operações de crédito imobiliário e, para tanto, gerenciava os recursos do Fundo de Garantia por Tempo de Serviço (FGTS), por intermédio de bancos privados e/ou públicos e de agentes promotores, como as Companhias Habitacionais e as Companhias de Água e Esgoto.

Após a criação do BNH foi criado também o Sistema Brasileiro de Poupança e Empréstimo para aumentar a captação de recursos originários da poupança privada. $\mathrm{O}$ principal objetivo do governo era proporcionar atendimento prioritário à população de baixa renda, financiando habitações e implantando infraestrutura urbana.

As tentativas de construção de um marco regulatório no âmbito federal para a política urbana datam desde as propostas de lei de desenvolvimento urbano elaboradas pelo então Conselho Nacional de Desenvolvimento Urbano nos anos 70. Com a promulgação da Constituição Federal de 1988, pela primeira vez na história, incluiu-se um capítulo específico (arts. 182 e 183 da $\mathrm{CF} / 88$ ) para a política urbana com a previsão de uma série de instrumentos 
para a garantia de sua efetividade, em cada município, da defesa da função social da propriedade e da democratização da gestão urbana.

$\mathrm{O}$ direito à moradia, reconhecido como inerente ao homem é direito a ser garantido pelo Estado, conforme o assegurado pela Constituição da República Federativa do Brasil de 1988. Essa formalização do direito à moradia se deu face ao contexto do imenso crescimento das cidades, por conta da industrialização e do desenvolvimento da tecnologia, os quais, atrelados à ideia de conforto, melhores condições de vida, oferta de emprego e possibilidade de aquisição de bens, principalmente da propriedade, passaram a criar nas pessoas a ilusão de que a vida nos grandes centros permitia a realização plena de seus sonhos.

No entanto, Romanelli (2008, p. 72) afirma que o processo de industrialização gerou elevado desequilíbrio das condições e da expectativa de vida, resultando num rápido processo de urbanização, porém com consequências muito drásticas, dentre elas a falta de moradia e o surgimento de áreas de ocupação irregular. O processo de urbanização das cidades foi tão intenso e rápido que o Estado não se deu conta das transformações ocorridas. A ocupação dos espaços ocorreu em contraposição aos serviços fornecidos pelo Estado, colocando em xeque sua capacidade de zelar pelo bem-estar da população.

Embora previsto no texto constitucional, não há como construir uma sociedade livre, justa e solidária, erradicar a pobreza e a marginalização, reduzir as desigualdades sociais e regionais e promover o bem de todos. Por conta disso, nasce o quadro crescente da segregação espacial, agravamento da miséria e desigualdade social.

Pinheiro (2008, p. 40) destaca que, até o advento da Constituição da República Federativa do Brasil de 1988, o espaço das cidades era protegido por ser um bem público, em sentido amplo, já que dentro do espaço das cidades encontram-se encravados bens de natureza privada, mesmo que estes sofram limitações de ordem pública. Com a nova Carta Magna, o espaço urbano passou à categoria de direito difuso, essencial à sadia qualidade de vida. Desse modo, a regulamentação da organização da cidade assumiu outra dimensão, já que a cidade configura bem essencial à sadia qualidade de vida - vida com dignidade - devendo, portanto, o aspecto difuso do meio ambiente artificial ser levado em consideração sempre que for deparado com um bem objeto de proteção do direito urbanístico. 
174

A Constituição da República Federativa do Brasil de 1988, em seu artigo 182, dispõe que "A Política de desenvolvimento urbano, executada pelo Poder Público municipal, conforme diretrizes fixadas em lei, tem por objetivo ordenar o pleno desenvolvimento das funções sociais da cidade e garantir o bem-estar de seus habitantes".

E o artigo 30 do mesmo diploma legal atribui ao Município a competência para promover o adequado ordenamento territorial, mediante planejamento e controle do uso, do parcelamento e da ocupação do solo urbano, assim como a competência suplementar residual (incisos I e II). Dessa forma, as principais funções sociais da cidade podem ser identificadas na promoção:

[...] da habitação, com a moradia digna, cabendo ao Poder Púbico proporcionar as condições de habitação adequada e fiscalizar sua ocupação, da circulação, por meio de um adequado sistema de transportes, do lazer, com a criação de praças e áreas verdes; e do trabalho, viabilizando o desenvolvimento das atividades laborais mediante a criação de espaços apropriados em que ele poderá desenvolver-se. (Pinheiro, 2008, p. 42).

O artigo 21, XX, da Carta Magna, atribui à União competência material para instituir diretrizes ao desenvolvimento urbano, inclusive habitação, saneamento básico e transportes urbanos. De acordo com a Constituição da República Federativa do Brasil de 1988, a propriedade urbana, encravada em espaço pertencente ao meio ambiente artificial, deve cumprir sua função social.

Cabe, portanto, ao Município com mais de 20 mil habitantes, por meio do plano, fixar as exigências fundamentais de ordenação da cidade, com vistas a limitar o direito de propriedade dos particulares e proporcionar, assim, sadia qualidade de vida a toda a coletividade.

Pinheiro (2008) explica que a origem das cidades tem como marco desencadeador as grandes mudanças, no que diz respeito à organização produtiva, já que essa forma de 
organização, transformou, ao longo da história, o cotidiano das pessoas, ocasionando, de maneira bastante acelerada, elevado desenvolvimento demográfico.

O Estatuto da Cidade - Lei n. 10.257 de 10 de julho de 2001 - disciplina o uso da propriedade urbana, as principais diretrizes do meio ambiente artificial, baseada no equilíbrio do meio ambiente, sempre observando os dispositivos jurídicos descritos nos artigos 182 e 183 da atual Constituição da República Federativa do Brasil. O artigo $2^{\circ}$, inciso I, do Estatuto da Cidade, tem como diretriz geral à garantia do direito às cidades sustentáveis, entendido como o direito à terra urbana, à moradia, ao saneamento artificial, à infraestrutura urbana, ao transporte e aos serviços públicos, ao trabalho e ao lazer, sempre levando em consideração a observância do princípio da dignidade da pessoa humana e seus destinatários, que são os brasileiros e os estrangeiros residentes no País.

Vale destacar que o direito à moradia garante o uso de determinada porção territorial no âmbito das cidades, denominado direito à casa, previsto no artigo $5^{\circ}$, XI, da Constituição Federal, para que se possa ter um local destinado a assegurar o asilo inviolável com a finalidade de garantir fundamentalmente o direito à intimidade, à vida privada (art. $5^{\circ}$, X), assim como a organização da família (arts. 226 a 230). A execução da política urbana, portanto, encontra-se prevista no Estatuto da Cidade, devendo pautar-se sempre na promoção da dignidade da pessoa humana.

O tratamento do tema moradia encontra-se, ainda, mais especificadamente definido, nos termos do artigo 23, IX, da Constituição da República Federativa do Brasil que atribui à União, aos Estados, ao Distrito Federal e aos Municípios, competência comum para a promoção de programas de construção de moradias e melhoria das condições habitacionais e de saneamento básico.

\section{Considerações finais}

Disso, conclui-se que, por força constitucional, os Municípios, como também a União, os Estados e o Distrito Federal, devem possuir programas e planos habitacionais visando à efetivação da política habitacional nacional, estadual e municipal, conforme o caso. Há de considerar-se imprescindível para a promoção do desenvolvimento urbano que a 
176

questão habitacional seja objeto de especial atenção. E, nesse sentido, conforme já salientado, existe o Estatuto da Cidade, que regulamenta os artigos 182 e 183 da Constituição Federal, os quais tratam da política de desenvolvimento urbano a ser executada pelos Poderes Públicos Nacional, Estadual e Municipal, por meio da gestão democrática.

Embora a moradia seja uma necessidade fundamental inerente ao homem, ela nasce, no Brasil, como direito a ser garantido pelo Estado com a promulgação da Constituição Federal de 1988. Incumbe ao Estado, portanto, além da obrigação de abster-se de ofender os direitos fundamentais, também a obrigação positiva da manutenção da ordem, no sentido de criar as condições favoráveis ao respeito à pessoa por parte de todos os que dependem de sua soberania. Ao Estado incumbe uma atuação estimuladora, assumindo papel de sujeito ativo da relação jurídica entre Estado-indivíduos, exigindo-se daquele, por meio de seus órgãos, atitude de limitar ou controlar o poder econômico privado, por intermédio de políticas públicas ou programas de ação governamental.

A formalização do direito à moradia deu-se com o contexto do imenso crescimento das cidades, que se teve com a industrialização e com o desenvolvimento da tecnologia, os quais, atrelados à ideia de conforto, melhores condições de vida, oferta de emprego e possibilidade de aquisição de bens, principalmente da propriedade, passaram a criar nas pessoas a ilusão de que a vida nos grandes centros permitia a realização plena de seus sonhos. No entanto, o processo de industrialização gerou acentuado desequilíbrio das condições e da expectativa de vida, resultando num elevadíssimo processo de urbanização, porém com consequências muito drásticas, dentre elas a falta de moradia e o surgimento das áreas de ocupação irregular.

A precariedade da habitação é, lamentavelmente, um dos problemas mais graves da sociedade brasileira, representando um dos custos mais caros nas sociedades contemporâneas submetidas ao sistema capitalista. Em um país com população predominantemente pobre e com capacidade comprometida para investimentos públicos, a habitação popular usualmente apresenta soluções temerárias, assistencialistas, dissonantes de condições dignas, sem qualquer segurança jurídica da posse e, nessas condições, por mais que esteja previsto no texto constitucional, são desafiantes as possibilidades de construção de uma sociedade livre, 
justa e solidária, com a erradição da pobreza e da marginalização, reduzindo-se as desigualdades sociais e regionais e promovendo o bem de todos.

Embora o sistema jurídico estatal parta do pressuposto de que todos os homens são iguais, há grupos sociais vivenciando que a igualdade propalada pelo Estado é uma mera ficção. Essa realidade impõe ao Estado brasileiro, que desde a sua origem se caracterizou por ser absenteísta, uma atuação intensa e direta em prol da moradia, por tratar-se de um requisito indispensável à vida e ao desenvolvimento nacional sustentável.

A elaboração das políticas públicas compete aos administradores, mas esse mérito pode ser sindicado pelo judiciário. Deve ser sindicado por ações coletivas que viabilizem o acesso de todos aos Direitos Fundamentais, sob pena de criação de odiosos privilégios em favor dos mais esclarecidos ou afortunados que buscam o acesso à justiça para "furar a fila" dos mais humildes que sequer têm consciência de seus direitos frente ao Estado.

As políticas públicas implantadas pelo Poder Público, no entanto, ainda se mostram insuficientes frente à deficitária realidade social que vivencia a esmagadora classe de excluídos.

Diante da realidade da pobreza e da miséria, no Brasil, somente as Políticas Públicas de Habitação popular poderão permitir a eficácia e a efetividade do Direito Fundamental à Moradia, garantido constitucionalmente.

\section{Referências}

GAZOLA, Patrícia Marques. Concretização do direito à moradia digna: teoria e prática. Belo Horizonte: Fórum, 2008.

HOLZ e MONTEIRO, Sheila e Tatiana Villela de Andrade. Política de habitação social e o direito a moradia no Brasil. Diez años de câmbios em el Mundo, em la Geografia y em lãs Ciências Sociales, 1999-2008. Actas del X Colóquio Internacional de Geocrítica, Universidade de Barcelona, 26-30 de mayo de 2008. Acesso em: http:www.ub.es/geocrit/xcol/158.thm. Acesso em: 28 de abr. 2010. 
MEIRELES, Hely Lopes. Direito municipal brasileiro. São Paulo: Saraiva, 2003.

NOLASCO, Lorecy Gottschalk. Direito fundamental à moradia. São Paulo: Pillares, 2008.

PINHEIRO, Carla. Direito ambiental. São Paulo: Saraiva, 2008.

POCHMANN e AMORIN, Atlas da exclusão social no Brasil. São Paulo: Cortez, 2003

ROMANELLI, Luiz Cláudio. Direito à moradia à luz da gestão democrática. 2. ed. revista e atualizada. Curitiba: Juruá, 2008.

SAULE JÚNIOR, Nelson. O direito à moradia como responsabilidade do Estado brasileiro. Caderno de pesquisa ao CEBRAP - Centro brasileiro de análises e planejamento, n. 7 , p. 65-80, maio 1997.

SOUZA, Sérgio Iglesias Nunes de. Direito à moradia e de habitação. Análise comparativa e suas implicações teóricas e práticas com os direitos de personalidade. 2. ed. revista, atualizada e ampliada. São Paulo: Revista dos Tribunais, 2008.

Artigo recebido em 02 de março de 2012 e aceito em 07 de junho de 2012. 